\title{
MANCHESTER
}

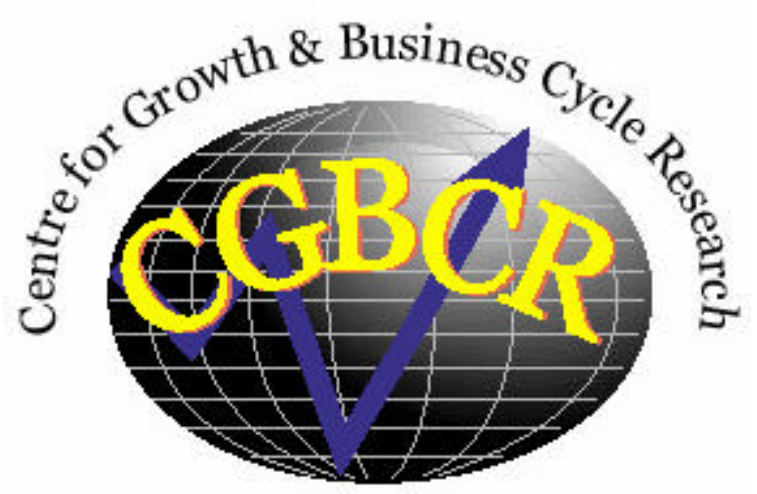

Discussion Paper Series

\section{Fiscal Policy and Endogenous Growth with Public Infrastructure \\ By}

\section{Pierre-Richard Agénor}

Centre for Growth and Business Cycle Research, Economic Studies,

University of Manchester, Manchester, M13 9PL, UK

September 2005

Number 059

Download paper from:

http://www.ses.man.ac.uk/cgbcr/discussi.htm 


\title{
Fiscal Policy and Endogenous Growth with Public Infrastructure
}

\author{
Pierre-Richard Agénor* \\ Hallsworth Professor of International Macroeconomics \\ and Development Economics \\ University of Manchester, United Kingdom \\ and Centre for Growth and Business Cycle Research
}

First complete draft: May 4, 2005

This version: September 11, 2005

\begin{abstract}
Optimal tax and spending allocation rules are derived in an endogenous growth model in which raw labor must be educated to become productive and infrastructure services affect the schooling technology. The optimal tax rate is found to depend only on the elasticities of output with respect to infrastructure services and educated labor. The optimal share of spending on infrastructure (relative to education) depends also on these elasticities, as well as the quality of schooling and the degree to which infrastructure services affect the production of educated labor. Congestion costs in education tend to raise the optimal share of spending on infrastructure.
\end{abstract}

JEL Classification Numbers: O41, H54, I28.

${ }^{*}$ I am grateful to Kyriakos Neanidis and other colleagues at the University of Manchester for helpful discussions on the issue discussed in this paper. I bear sole responsibility, however, for the views expressed here. 


\section{Contents}

1 Introduction 3

2 The Model $\quad 7$

2.1 Production .................... . . 7

2.2 Household Preferences . . . . . . . . . . . . . . . 8

2.3 Human Capital Accumulation . . . . . . . . . . . . . . . . 9

2.4 Government . . . . . . . . . . . . . . . . . 10

3 The Decentralized Equilibrium $r$

4 Revenue-Neutral Spending Shift $\quad 14$

5 The Growth-Maximizing Fiscal Structure 16

6 Congestion Costs 19

7 Concluding Remarks $\quad 21$

$\begin{array}{lr}\text { Appendix } & 24\end{array}$

$\begin{array}{lr}\text { References } & 29\end{array}$

Figure 1: The Balanced Growth Equilibrium 32

Figure 2: Shift in the Composition of Government Spending from Education to Infrastructure $\quad 33$ 


\section{Introduction}

The impact of public investment on growth has been the subject of much attention in recent academic research and policy debates (see Zagler and Durnecker (2003) for an overview). Research has focused in particular on the effects of public infrastructure, both at the empirical and analytical levels. At the empirical level, Easterly and Rebelo (1993), in an early contribution, found a positive association across countries between public investment in infrastructure (transportation and communications) and growth. In a "rerun" of the Easterly-Rebelo regressions, Miller and Tsoukis (2001) confirmed this effect. ${ }^{1}$ Bose, Haque, and Osborn (2003), using panel data for 30 developing countries and an econometric methodology that explicitly accounts for the government budget constraint and possible biases arising from omitted variables, found that the share of government capital expenditure in GDP is positively and significantly related to income growth per capita, whereas the share of current expenditure is not. Calderón and Servén (2004), using a large sample of countries and panel data covering the period 1960-2000, found that growth is positively affected by the stock of infrastructure assets. ${ }^{2}$ Loayza, Fajnzylber, and Caldéron (2004) found that public infrastructure (measured by the number of telephone lines per capita) has a positive and significant effect on growth in Latin America and the Caribbean. Albala-Bertrand and Mamatzakis (2004) found that in Chile, public infrastructure capital had a positive effect on private investment in recent years and thus, indirectly, on

\footnotetext{
${ }^{1}$ Whereas Easterly and Rebelo (1993) found no effect of infrastructure investment on private capital formation, and no effect of total public investment on growth, Miller and Tsoukis (2001) also found a positive and significant effect of overall public investment on growth.

${ }^{2}$ In contrast to Bose, Haque, and Osborn (2003), Calderón and Servén (2004) do not account for the govenrment budget constraint in their estimation. As a result, their simulation exercises should be viewed with caution.
} 
growth. Gupta et al. (2005), in a study focusing on 39 low-income countries during the 1990s, found that the composition of public expenditure matters significantly in assessing the effects of fiscal policy on economic growth. Countries where a large fraction of government spending consists of wages and transfers tend to have slower growth, whereas countries where higher shares of spending are allocated to capital and nonwage goods and services tend to have faster growth. ${ }^{3}$

At the analytical level, much effort has also been devoted to analyzing the growth effects of public investment (particularly in infrastructure), in the context of endogenous growth models. A series of contributions, following an early paper by Barro (1990), treat public investment as a flow-see, for instance, Turnovsky and Fisher (1995), Corsetti and Roubini (1996), Chang (1999), Fiaschi (1999), Turnovsky (2000), Eicher and Turnovsky (2000), and Rivas (2003). By contrast, contributions by Futagami, Morita, and Shibata (1993), Fisher and Turnovsky (1998), Dasgupta (1999), Rioja (1999), and Turnovsky (1997, 2004), among others, treat public infrastructure as a stock. These studies have provided much insight into the determinants of growthand welfare- maximizing shares of public investment in infrastructure. For instance, Barro's key result, in a model where public spending takes the form only of production-enhancing services, was shown by Futagami, Morita, and Shibata (1993) to remain valid in a setting where it is the public capital stock, rather than the flow of public spending, that affects production. Other researchers have focused on the broader issue of the optimal fiscal structure, that is, the simultaneous determination of optimal tax and expenditure rates. Turnovsky (1996) for instance, considered the determination of the optimal

\footnotetext{
${ }^{3}$ It should be noted, however, that this study, like many along the same line, does not account for spending on maintenance.
} 
consumption and income tax rates, the share of government spending on output, and optimal debt in an endogenous growth framework. Addressing the issue of the optimality of the overall fiscal structure is important for the design of fiscal reform, given the possible interdependence between tax collection and the allocation of public resources among alternative forms of expenditure.

This paper contributes to the existing literature by focusing on the determination of the optimal tax and expenditure structure in a growth context, as in Turnovsky (1996). However, unlike Turnovsky, I do so in an endogenous growth model with both physical and human capital accumulation, and a government that provides infrastructure, education, and utility-enhancing services. As in Agénor (2004), the model assumes that the economy is endowed only with "raw" labor, and that raw labor must be educated to become productive. Knowledge is thus embodied in (educated) workers, unlike Lucas-type models where human capital is disembodied and can therefore grow without bounds. Moreover, in the model infrastructure has a positive effect on the rate of human capital accumulation. This specification captures the view that infrastructure services (better roads, reliable access to electricity, etc.) may enhance the ability of individuals to study and acquire skills. This is a particularly important consideration for low-income developing countries. In many of these countries, the lack of an adequate network of roads makes access to schools (particularly in rural areas) difficult; dropout rates tend to be higher when children must walk long distances to get to school. The lack of access to electricity hampers the ability to study, both in the classroom and at home. In some countries, the lack of adequate toilet facilities for girls in rural area schools has led many parents to deny an education to their daughters. As it turns out, accounting for the impact of 
infrastructure on the schooling technology has important implications for the determination of the optimal allocation of government expenditure.

Another issue that I address in the paper is the existence of congestion costs in education. Again, this is a particularly important factor in determining the quality of schooling in low-income countries, where (according to recent data from UNESCO and the World Bank) student-teacher ratios may dramatically exceed average ratios in industrial countries. For instance, at 44 to 1 , the pupil-teacher ratio in sub-Saharan Africa is on average three times higher than that of developed countries; moreover, one in four countries in the region has ratios above 55 to 1 (see UNESCO (2005)). Much research has examined the issue of congestion costs in infrastructure, and their implications for private capital formation and the optimal allocation of public expenditure (see, for instance, Turnovsky (1997), Fisher and Turnovsky (1998), and Eicher and Turnovsky (2000)). But almost none has focused on congestion costs in education. ${ }^{4}$ As discussed later, the existence of these costs also has important implications for determining the growth-maximizing allocation of public spending.

The remainder of the paper proceeds as follows. Section II presents the model. Section III solves for the steady-state growth rate in the decentralized equilibrium, and examines its dynamic properties. Section IV illustrates the functioning of the model by considering a revenue-neutral change in the composition of public spending, namely a switch from spending on education to infrastructure services. Section IV derives the growth-maximizing fiscal structure. Section V introduces congestion costs in education in the model,

\footnotetext{
${ }^{4}$ Evidence on the impact of the quality of schooling (as proxied by international differences in mathematics and science test scores) on growth is provided by Hanushek and Kimko (2000). Note also that quality can depend also on the intensity of instruction, that is, the number of contact hours per student year (see UNESCO (2005)).
} 
and examines the effect of these costs on the optimal allocation of government expenditure. The final section summarizes the main results of the paper and offers some concluding remarks.

\section{The Model}

Consider an economy populated by an infinitely-lived representative household who produces a single traded good, whose price is fixed on world markets. The good can be used for either consumption or investment. The economy's endowment consists of raw labor, which must be educated (through a publicly-funded schooling system) to be used in the production process. The government provides at no charge infrastructure, education and utilityenhancing services. It levies a flat tax on output to finance its expenditure.

\subsection{Production}

Output, $Y$, is produced with private physical capital, public infrastructure services, educated labor, using a Cobb-Douglas technology: ${ }^{5}$

$$
Y=G_{I}^{\alpha}(\chi E)^{\beta} K_{P}^{1-\alpha-\beta}=A_{P}\left(\frac{G_{I}}{K_{P}}\right)^{\alpha}\left(\frac{E}{K_{P}}\right)^{\beta} K_{P}
$$

where $K_{P}$ is the stock of private capital, $G_{I}$ government infrastructure services, $E$ the stock of educated labor, $\chi \in(0,1)$ the proportion of the educated labor force employed in production, $A_{P} \equiv \chi^{\beta}>0$, and $\alpha, \beta \in(0,1)$. Thus, production exhibits constant returns to scale in all factors. In the present framework, constant returns to scale in reproducible factors $\left(E\right.$ and $\left.K_{P}\right)$ is not necessary to generate permanent growth. As long as $G_{I} / K_{P}$ and $E / K_{P}$ are constant (which turns out to be the case in the steady state), output will

\footnotetext{
${ }^{5}$ Throughout the paper, the time subscript $t$ is omitted. A dot over a variable is used to denote its time derivative.
} 
exhibit linearity in the stock of private capital. The production function is then essentially an $A K$-type technology.

\subsection{Household Preferences}

The infinitely-lived representative household-producer maximizes the discounted stream of future utility

$$
V=\int_{0}^{\infty}\left[\frac{C^{1-\theta}}{1-\theta}+\phi \ln G_{H}\right] \exp (-\rho t) d t, \quad-\infty<\theta \leq 1,
$$

where $C$ is consumption, $G_{H}$ utility-enhancing government services, $\rho>0$ the discount rate, $\sigma=1 / \theta$ the intertemporal elasticity of substitution (with $\theta=1$ corresponding to the logarithmic utility function), and $\phi>0$ a coefficient that measures the impact of $G_{H}$ on the household's instantaneous utility. Thus, as for instance in Turnovsky (1996, 2000, 2004), Chang (1999), and Baier and Glomm (2001), publicly-provided services affect the household's utility directly. However, unlike these authors, and in line with Cassou and Lansing (2003), private consumption and public services are assumed to be additively separable. This is in line with the empirical evidence provided by Karras (1994), McGrattan, Rogerson and Wright (1997), Chiu (2001), and Okubo (2003), among others.

Output is taxed at the rate $\tau \in(0,1)$. The household spends on consumption and accumulates capital. It receives from the government teachers' pay, $(1-\chi) w_{G} E$, where $w_{G}$ is the real wage and $1-\chi$ the proportion of teachers in the educated labor force. AS noted earlier, education is provided free of charge and there are no user fees for infrastructure services used in production. Thus, public spending-related production rents accrue to the household. Abstracting from capital depreciation, the household's resource constraint is

$$
C+\dot{K}_{P}=(1-\tau) Y+(1-\chi) w_{G} E .
$$




\subsection{Human Capital Accumulation}

Raw labor, which grows at a constant rate, $n$, must be educated before it can be used in the production process. The production of educated labor requires the combination of teachers, students, and government infrastructure services:

$$
\dot{E}=Q[(1-\chi) E]^{\kappa} G_{I}^{\mu} L^{1-\kappa-\mu}
$$

where $\dot{E}$ is the flow of newly-educated workers, $L$ the number of students, $Q$ a variable that measures the quality of schooling, and $\kappa, \mu \in(0,1)$. Thus, the education technology exhibits constant returns to scale in $E, G_{I}$, and $L$.

Quality is an increasing function of the ratio of government spending on education, $G_{E}$, and the number of teachers:

$$
Q=\left[\frac{G_{E}}{(1-\chi) E}\right]^{\eta},
$$

where $\eta \in(0,1)$. This specification indicates therefore that the quality of education exhibits decreasing returns to scale with respect to $G_{E} / E$. Increasing the number of teachers for instance, without increasing at the same time spending on items such as books, writing materials, meals for students, and so on, would reduce the ability of the education system to produce educated labor.

Combining (4) and (5) yields

$$
\dot{E}=(1-\chi)^{\kappa-\eta}\left(\frac{G_{E}}{E}\right)^{\eta}\left(\frac{E}{L}\right)^{\kappa+\mu}\left(\frac{G_{I}}{E}\right)^{\mu} L .
$$

In what follows, I ignore depreciation (or de-skilling) of educated labor. I also assume that the government's "admission" policy for students in the education system is such that it keeps the student-teacher ratio constant:

$$
\frac{L}{(1-\chi) E}=a
$$


where $a>0$. This rule implies that, along the balanced growth path, where $E$ grows at a constant rate, $L$ must also grow at the same constant rate. Moreover, to ensure that this equality holds continuously, I assume that the growth rate of the total population of raw labor (from which students are selected), $n$, is greater than the steady-state growth rate of $E$.

Using (7), equation (6) can be rewritten as

$$
\frac{\dot{E}}{E}=A_{E}\left(\frac{G_{E}}{E}\right)^{\eta}\left(\frac{G_{I}}{E}\right)^{\mu},
$$

where $A_{E} \equiv a^{1-\kappa-\mu}(1-\chi)^{1-\eta-\mu}$. Thus, the growth rate of the stock of educated labor depends on public spending on both education and infrastructure services per teacher (or educated worker). Note also that, as a result of (7), it does not matter whether the quality of schooling is defined as a function of the ratio of government spending per teacher (as in (5)) or per student.

\subsection{Government}

The government provides infrastructure, education, and utility-enhancing services to the representative household, pays salaries to teachers, and collects a proportional tax on output. It cannot issue debt and must maintain a balanced budget continuously. ${ }^{6}$ Thus, the government's flow budget constraint is given by

$$
\sum_{h=I, E, H} G_{h}+(1-\chi) w_{G} E=\tau Y .
$$

Expenditure on all categories of services are taken to be determined as fractions of tax revenue, so that $G_{h}=v_{h} \tau Y$, with $v_{h} \in(0,1)$, and $h=$

\footnotetext{
${ }^{6}$ See Turnovsky $(1996,1997)$ for the case of debt financing in a similar context. Because Ricardian Equivalence holds in the present framework, excluding borrowing is simply a matter of convenience. With government borrowing, agents would foresee that higher taxation would be required later in order to repay the accumulated debt, and this would need to be accounted for.
} 
$I, E, H$. Teachers' salaries are also fixed as a fraction $\varphi$ of tax revenue. The government budget constraint therefore implies that

$$
\sum_{h=I, E, H} v_{h}+\varphi=1
$$

which determines residually one of the spending shares.

From (3) and (9), the market-clearing condition for the goods market is

$$
Y=C+\dot{K}_{P}+\sum_{h=I, E, H} G_{h}
$$

\section{The Decentralized Equilibrium}

In the present setting, a decentralized equilibrium can be defined as follows:

Definition 1. A competitive equilibrium is a set of infinite sequences for the quantities $\left\{C, K_{P}, E\right\}_{t=0}^{\infty}$, such that $\left\{C, K_{P}\right\}_{t=0}^{\infty}$ maximizes equation (2) subject to (3), and the path $\left\{K_{P}, E\right\}_{t=0}^{\infty}$ satisfies equations (8), (10), and (11), for given values of the tax rate, $\tau$, the ratio of government wages to output, $\varphi$, and the spending shares on services, $v_{h}$, with $h=I, E, H$.

This equilibrium can be characterized as follows. The household-producer maximizes (2) subject to (3), taking the tax rate, $\tau$, government services and wage payments, $G_{H}$ and $(1-\chi) w_{G} E$, as given. The current-value Hamiltonian for this problem can be written as

$$
\Lambda=\frac{C^{1-\theta}}{1-\theta}+\phi \ln G_{H}+\lambda\left[(1-\tau) Y+(1-\chi) w_{G} E-C\right],
$$

where $\lambda$ is the costate variable associated with constraint (3). Using (1), first-order optimality conditions for this problem can be written as, setting $s \equiv(1-\tau)(1-\alpha-\beta)$, so that $s \in(0,1)$ :

$$
\frac{d \Lambda}{d C}=0 \Longrightarrow C^{-\theta}=\lambda
$$




$$
\rho-\dot{\lambda} / \lambda=\frac{d \Lambda}{d K_{P}}=s A_{P}\left(\frac{G_{I}}{K_{P}}\right)^{\alpha}\left(\frac{E}{K_{P}}\right)^{\beta},
$$

together with the budget constraint (3), the initial condition $K_{P}(0)=K_{P}^{0}$, and the transversality condition

$$
\lim _{t \rightarrow \infty} \lambda K_{P} \exp (-\rho t)=0
$$

Equation (12) equates the marginal utility of consumption to the shadow value of private capital, $\lambda$. Equation (13) is the standard Keynes-Ramsey consumption rule, which equates the rate of return on consumption (given by the term on the left-hand side) to the after-tax marginal physical product of private capital (equal to $1-\tau$ times $\partial Y / \partial K_{P}$ ).

Combining Equations (12) and (13) yields

$$
\frac{\dot{C}}{C}=\sigma\left[s A_{P}\left(\frac{G_{I}}{K_{P}}\right)^{\alpha}\left(\frac{E}{K_{P}}\right)^{\beta}-\rho\right],
$$

whereas substituting (1) in (3) yields

$$
\dot{K}_{P}=(1-\tau) A_{P}\left(\frac{G_{I}}{K_{P}}\right)^{\alpha}\left(\frac{E}{K_{P}}\right)^{\beta} K_{P}+(1-\chi) w_{G} E-C .
$$

As shown in the Appendix, equations (8), (10), (15), and (16) can be further manipulated to lead to a system of two nonlinear differential equations (see equations (A7) and (A8)) in $c=C / K_{P}$ and $e=E / K_{P}$. These two equations, together with the initial condition $e_{0}=E_{0} / K_{P}^{0}>0$, and the transversality condition (13), rewritten as

$$
\lim _{t \rightarrow \infty} c^{-1} \exp (-\rho t)=0
$$

determine the dynamics of the decentralized economy. The balanced-growth equilibrium (BGE) can therefore be defined as follows: 
Definition 2. The BGE is a set of sequences $\{c, e\}_{t=0}^{\infty}$, spending shares and tax rate satisfying Definition 1, such that for an initial condition e equations (8) (15), and (16) and the transversality condition (17) are satisfied, and consumption, the stock of educated labor, and the stock of private capital, all grow at the same constant rate $\gamma=\dot{C} / C=\dot{E} / E=\dot{K}_{P} / K_{P}$.

The transversality condition (17) is always satisfied along any interior BGE because consumption and the stock of private capital grow at the same constant rate, implying that the ratio $c=C / K_{P}$ is also constant. ${ }^{7}$ Given the form of the utility function used here, a necessary condition to get bounded utility (that is, for the integral in (2) to converge) is $\rho>(1-\theta) \gamma$. This condition imposes no restriction when $\theta>1$. When $\theta<1$, it imposes an upper bound on admissible values for the rate of growth. Equivalently, it requires the rate of time preference to be sufficiently large.

From equations (A4) and (A6) in the Appendix, $\gamma$ is given by the equivalent forms ${ }^{8}$

$$
\begin{aligned}
& \gamma=s \sigma A_{P}\left(v_{I} \tau\right)^{\alpha /(1-\alpha)} \tilde{e}^{\beta /(1-\alpha)}-\sigma \rho \\
& \gamma=A v_{E}^{\eta} v_{I}^{(\alpha \eta+\mu) /(1-\alpha)} \tau^{(\eta+\mu) /(1-\alpha)} \tilde{e}^{\omega}
\end{aligned}
$$

where $\tilde{e}$ denotes the steady-state value of $e, A$ a constant term, and

$$
\omega=\frac{(\eta+\mu)(\alpha+\beta-1)}{1-\alpha}<0
$$

As shown in the Appendix, the following proposition can be established:

${ }^{7}$ Note also that from (1), because $\dot{E} / E=\dot{K}_{P} / K_{P}$,

$$
\frac{\dot{Y}}{Y}=\alpha \frac{\dot{G}_{I}}{G_{I}}+[\beta+(1-\alpha-\beta)] \frac{\dot{K}_{P}}{K_{P}},
$$

and because $G_{I}=v_{I} \tau Y$ (so that the growth rates of $G_{I}$ and $Y$ are the same), output also grows at rate $\gamma$.

${ }^{8}$ Equation (A3) in the Appendix provides a third equivalent form of $\gamma$. But it can easily be shown that, given the steady-state solution for $c$, it is in fact equivalent to (18). 
Proposition 1. Along an equilibrium path with a strictly positive growth rate, the BGE is unique. There is only one stable path converging to this equilibrium.

This proposition implies therefore that the model is locally determinate. Its dynamics can be analyzed using phase diagrams, as illustrated in Figure 1. The $\dot{e}=0$ curve (denoted $E E$ in the figure) always has a positive slope in $c$-e space, whereas the slope of the $\dot{c}=0$ curve (denoted $C C$ ) can be either upward- or downward-sloping, depending on the size of the elasticity of intertemporal substitution, $\sigma$. The upper (lower) panel corresponds to the case where $\sigma$ is relatively high (low), in a sense made precise in the Appendix. The saddlepath, denoted $S S$, may therefore have either a positive or negative slope. Following a jump in $c$ (as a result, for instance, of a change in the tax rate or one of the spending shares parameters), $c$ and $e$ may or may not move in the same direction. The reason is that the transitional dynamics are driven by the ratio of educated labor to private capital, and as this ratio increases (falls), the marginal productivity of private capital increases (falls) as well. In turn, this tends to raise (reduce) consumption and investment over time.

\section{Revenue-Neutral Spending Shift}

The steady-state effects and transitional dynamics associated with revenueneutral changes in spending shares are straightforward to analyze in the present setting. In particular, the Appendix establishes that an increase in $v_{I}$, offset by a reduction in $v_{E}$ (that is, with $d v_{I}+d v_{E}=0$, holding $\tau$ and $\varphi$ constant), has an ambiguous effect on the steady-state growth rate, as summarized in the following proposition: 
Proposition 2. With the tax rate and the share of government spending on wages held constant, a switch in the composition of public expenditure from education to infrastructure services has an ambiguous effect on the steady-state growth rate. If infrastructure services do not affect the education technology $(\mu=0)$, the net effect depends only on $\alpha / \beta$. With $\mu>0$, the net effect depends also on $\mu / \eta$.

To understand the intuition behind these results, consider first the case where $\mu=0$. Increasing the fraction of government spending on infrastructure (for a given stock of educated labor) increases the marginal product of physical capital, which, in turn, raises investment and steady-state growth. At the same time, however, because the change is revenue neutral $\left(d v_{I}=\right.$ $\left.-d v_{E}\right)$, the ratio of educated labor-physical capital unambiguously falls, as long as $\eta>0$. Thus, the positive effect of the increase in the share of spending on infrastructure is accompanied by a lower supply of educated workers, which tends to lower private production and reduce the growth rate. The net effect on output and the growth rate, depends on how "productive" the two inputs are in relative terms, that is, on the ratio $\alpha / \beta$. As shown in the Appendix, if $\alpha / \beta$ exceeds the elasticity of the steady-state value of the educated labor-capital ratio with respect to the share of spending in infrastructure, the growth effect (as well as the effect on the consumption-capital ratio) will be positive.

With $\mu>0$, the net effect on the steady-state ratio of educated labor to physical capital is also ambiguous; it now depends on related not only to how productive the two types of services are in the production of goods, but also to how productive they are in the production of educated labor, as measured by the ratio $\mu / \eta$. Even if infrastructure services have a small impact on the production of goods, a high ratio $\mu / \eta$ may still imply an increase in $\tilde{e}, \tilde{c}$, and 
$\gamma$. In the particular case where $\eta=0$, that is, if education services do not affect the acquisition of skills, the effect on the steady-state growth rate is unambiguously positive.

Figure 2 illustrates two possible outcomes, with a relatively high value of the elasticity of intertemporal substitution and a ratio $\mu / \eta$ that is not too large. In both cases, therefore, the educated labor-capital ratio falls in the steady state. But the consumption-capital ratio and the growth rate may either increase or fall, depending on the magnitude of $\alpha / \beta$, as noted earlier. In both panels curve $C C$ shifts to the left, but curve $E E$ can shift either to the right (upper panel) or the left (lower panel). In the upper (lower) panel, $C C$ shifts by more (less) than $E E$ and the consumption-capital ratio falls (increases). The steady-state consumption-capital ratio falls in the first case and increases in the second. ${ }^{9}$ As noted ealier, during the transition, the fall in the educated labor-capital ratio lowers the marginal productivity of capital, leading to a gradual reduction in the stock of physical capital. This reduction is large enough to ensure that the consumption-capital ratio increases over time.

\section{The Growth-Maximizing Fiscal Structure}

To determine the growth-maximizing fiscal structure in the decentralized equilibrium involves setting simultaneously the tax rates and expenditure shares, so that $\partial \gamma / \partial \tau=\partial \gamma / \partial v_{h}=0, \forall h$. Given the structure of the model, this problem can be addressed in two stages, the first of which involves solving for the optimal rate, subject to the constraints that spending shares are

\footnotetext{
${ }^{9}$ In both cases, the impact effect is shown as operating in the same direction as the long-run effect. However, this is always true only if the consumption-capital ratio increases in the steady state.
} 
exogenous. From (18) and (19), the following proposition can be readily established:

Proposition 3. With all government spending shares held constant, the growth-maximizing value of the tax rate is $\tau^{*}=\alpha+\beta$.

This result generalizes the rule $\tau^{*}=\alpha$, which was first established by Barro (1990) in a flow model, and subsequently in stock models by Futagami, Morita, and Shibata (1993), Turnovsky (1997), and Baier and Glomm (2001). The Barro rule is obtained only in the particular case where educated labor (or, more generally, human capital) has no effect on production, that is, $\beta=0$. Note, however, that the optimal tax rate depends only on parameters characterizing the goods production technology; it is independent not only of how the revenue is spent (that is, the spending shares $v_{h}$ and $\varphi$ ) but also of the parameters characterizing the education technology.

The second stage involves allocating public expenditure between infrastructure, education and utility-enhancing services, with the tax rate and the share of government spending on wages both taken as given. The following proposition can be shown to hold:

Proposition 4. With the tax rate and the share of government spending on wages held constant, the growth-maximizing composition of public expenditure is

$$
v_{H}^{*}=0, \quad \frac{v_{I}^{*}}{v_{E}^{*}}=\frac{\alpha}{\beta}+\frac{\mu}{\eta}\left(1+\frac{\alpha}{\beta}\right) .
$$

That the optimal value of $v_{H}^{*}$ is zero is of course a direct implication of assuming separability between utility-enhancing government services and private consumption. As a consequence, spending on this type of services has no effect on growth, as noted earlier. To provide a more intuitive inter- 
pretation the second result, it is convenient to consider the particular case where $\varphi=0$. Given (10), Proposition 4 implies therefore that

$$
v_{E}^{*}=\frac{\beta}{\alpha+\beta}\left(1+\frac{\mu}{\eta}\right)^{-1}=\frac{\eta \beta}{(\alpha+\beta)(\eta+\mu)}<1, \quad v_{I}^{*}=1-v_{E}^{*} .
$$

Equation (20) implies that if the production function for educated labor does not depend on infrastructure services, that is, with $\mu=0$, the optimal allocation of spending between infrastructure and education would depend only on the parameters characterizing the goods production technology (the ratio $\alpha / \beta$ ) not on the education technology, as I have shown elsewhere (see Agénor (2004)). In addition, from (21) the optimal shares would thus be $v_{I}^{*}=\alpha /(\alpha+\beta)$ and $v_{E}^{*}=\beta /(\alpha+\beta)$, and, from Proposition 3, the shares of spending in output would be $\tau^{*} v_{I}^{*}=\alpha$ and $\tau^{*} v_{E}^{*}=\beta .{ }^{10}$ In the general case where $\mu>0$, however, the education technology does matter for the allocation of government spending; the optimal share of spending on education (infrastructure) is lower (higher) than otherwise. As can be inferred from (20), the more productive infrastructure services are in fostering the acquisition of skills (the higher $\mu$ is), or the lower the quality of education (the lower $\eta$ is), the higher should be the optimal share of spending on infrastructure services. Note also that an improvement in the quality of education has no effect on the optimal allocation of public expenditure if infrastructure services do not affect the production of educated labor. And in the limit case where $\eta \longrightarrow 0$ (so that public spending on education has no effect on the schooling technology), $v_{E}^{*} \longrightarrow 0$ (or, equivalently, $v_{I}^{*} \longrightarrow 1$ ), as could be expected.

Given that the optimal tax rate is independent from spending shares, and conversely that the optimal shares are independent of the tax rate, the results

\footnotetext{
${ }^{10}$ The result $\tau v_{I}=\alpha$ was also derived by Lee (1992) in a model without human capital accumulation.
} 
in Propositions 3 and 4 indeed summarize the optimal fiscal structure in a decentralized economy. The issue to which I turn next is the extent to which the degree of congestion in the education technology affects the optimal tax rate and spending shares.

\section{Congestion Costs}

As noted earlier, much of the endogenous growth literature on congestion costs has focused so far on two types of congestion costs: those affecting the use of infrastructure services (or capital) in the production of goods, and those affecting utility-enhancing services. ${ }^{11}$ In the context of the present paper, a more novel issue to consider is the case where it is the use of infrastructure services in the education technology that is subject to congestion. A related issue is the extent to which the quality of education depends on how crowded classrooms are, with congestion taking the form of threshold effects.

Specifically, two alternative ways of modeling congestion costs in education are considered. The first approach consists of assuming that the productivity of infrastructure services falls with an increase in the flow number of students (or newly-educated individuals), $\dot{L}$ :

$$
\dot{E}=Q[(1-\chi) E]^{\kappa}\left(\frac{G_{I}}{\dot{L}^{\delta}}\right)^{\mu} L^{1-\kappa-\mu},
$$

where $\delta \geq 0$ measures the degree of congestion (with $\delta=1$ denoting proportional congestion). For instance, too many students using publicly-provided internet services may slow the speed of access for everybody, thereby diminishing the usefulness of these services for creating educated labor. Given that

\footnotetext{
${ }^{11}$ For examples of the former literature, see Turnovsky (1997), Fisher and Turnovsky (1998), and Glomm and Ravikumar (1999); for examples of the latter, see Turnovsky (1996), Rioja (1999), and Piras (2004).
} 
from $(7), \dot{E}=\dot{L}$, it is straightforward to show that using equation (22) instead of (4) does not affect any of the previous results regarding the optimal fiscal structure (Propositions 3 and 4). The reason is clear-equation (22) boils down to a geometric transformation (will all coefficients multiplied by $\left.(1+\delta \mu)^{-1}\right)$ of the original expression for educated labor flows. Although this changes the stability properties of the model and its transitional dynamics (and thus the speed of convergence to the BGE), it does not alter the optimal allocation rule because it is the ratio $\mu / \eta$ that appears in Proposition $4 .^{12}$

The second approach to account for congestion in the production of educated labor is to assume that quality is subject to threshold effects. In the foregoing analysis, it was assumed throughout that the ratio of students to teachers, $L /(1-\chi) E$ (denoted by $x$ below) is kept fixed at $a$ by the government. However, whether $a$ is "high" or "low" has obvious implications for the quality of schooling. Specifically, suppose that the quality of education, $Q$, has a parameter $\eta$ that can be high or low $\left(\eta_{H}\right.$ or $\eta_{L}$, respectively), depending on whether the student-teacher ratio is lower or greater than a threshold value, $a_{C}$ :

$$
Q=\left\{\begin{array}{ll}
Q_{H}=x^{\eta_{H}}, & \text { if } a \leq a_{C} \\
Q_{L}=x^{\eta_{L}}, & \text { if } a>a_{C}
\end{array} .\right.
$$

This specification implies that the model can generate multiple BGEs, a full characterization of which is beyond the scope of this paper. For the purpose at hand, it is sufficient to observe that, from Proposition 4, the two regimes would be characterized by different optimal allocations between infrastructure and education services: in the $\eta_{L}$-regime, the optimal share $v_{E}^{*}$ would indeed be lower than in the $\eta_{H^{-}}$-regime. These results can be summarized in the following proposition:

\footnotetext{
${ }^{12}$ However, the steady-state levels of both $c$ and $e$ are lower.
} 
Proposition 5. Congestion costs in education (in the form of threshold effects on the quality of schooling) raise the optimal share of public spending allocated to infrastructure.

Because the optimal tax rate does not depend on the parameters characterizing the education technology, Proposition 3 is not affected.

\section{Concluding Remarks}

The purpose of this paper was to study the determination of optimal taxation and allocation of public resources between utility-enhancing, infrastructure, and education services. The analysis was based on an endogenous growth model with two key features: raw labor must be educated to become productive and infrastructure services affect the schooling technology. Government spending is financed by a tax on output. The balanced growth equilibrium was derived, and the transitional dynamics associated with an shift in the composition of public spending from education to infrastructure services were analyzed. It was shown that, in general, this shift has an ambiguous effect on the growth rate and the steady-state values of the consumption-capital and educated labor-capital ratios.

The third part of the paper focused on the determination of the optimal tax rate and spending shares. The optimal tax rate was found to be equal to the sum of the elasticities of output with respect to infrastructure services and educated labor, and thus to be independent of the schooling technology. The optimal composition of public spending was shown to be a zero share for utility-enhancing services, whereas the optimal allocation to infrastructure (education) services was found to be positively (negatively) related to the degree to which infrastructure services affect the production of educated 
labor, and negatively (positively) to the quality of schooling. If infrastructure services are not education-enhancing, the optimal allocation between infrastructure and education would depend solely on the parameters characterizing the goods production technology. Finally,under the assumption that congestion costs in education take the form of threshold externalities associated with the quality of schooling, the optimal share of spending on infrastructure (education) was shown to be positively (negatively) related to the degree of congestion in education.

The analysis in this paper could be extended in several directions. A first area of investigation would be to consider the case where it is the stock of public capital in infrastructure, rather than the flow of spending on infrastructure services, that affect the production technology for goods and educated labor. I have pursued this line of research in a companion paper (see Agénor (2005a)), and the results indicate that the optimal rules remain qualitatively similar to those derived in the present paper. A second direction would be to consider other forms of distortionary taxation, such as a tax on consumption, wages, or capital income, as for instance in Turnovsky (2000). With an endogenous supply of (raw) labor, a tax on wages would also affect private decisions between labor and leisure, and the rate of growth. A tax on the returns from private capital would affect decisions between consumption and investment. Both taxes are likely to have ambiguous effects on growth, because their adverse effect on private investment and labor supply are offset by an increase in the stock of public capital.

A third potentially fruitful area of research relates to the role of utilityenhancing public services. In the model presented in this paper, the utility function of the representative household was assumed to be additively separable between private consumption and public services, as suggested by 
some of the empirical evidence. This specification implies that with the tax rate and the share of government spending on wages held constant, a switch in the composition of public expenditure from utility-enhancing services to the provision of either infrastructure or education services is unambiguously growth-enhancing. This result is of course due to the fact that the share of spending on utility-enhancing services has no effect on the economy's steady-state growth rate, neither directly or indirectly (through changes in the steady-state value of the ratio of educated labor to physical capital).

However, while separability may be intuitively obvious for some categories of utility-enhancing public services (such as security or national defense), this is not quite so for others, such as health services. Better health care, for instance, may have a direct impact on the ability of individuals to consume and enjoy their free time. In addition, better health may also affect the ability to produce and study. With a more general (non-separable in $C$ and $G_{H}$ ) utility function, the zero share result mentioned above would not hold, as can be inferred from the results of Lee (1992), Baier and Glomm (2001), and Turnovsky (1997, 2004). Indeed, with non separability in preferences, and possibly an effect of $G_{H}$ on production of goods and educated labor (because these services are health-enhancing, for instance, and therefore increase the productivity of production workers, students, as well as teachers) it would not be optimal to allocate a zero share to that category of spending. Determining how exactly the optimal rules are affected would represent therefore a worthwhile complement to the present analysis. 


\section{Appendix}

Substituting (9) in (16) using $G_{h}=v_{h} \tau Y$ yields

$$
\dot{K}_{P}=q A_{P}\left(\frac{G_{I}}{K_{P}}\right)^{\alpha}\left(\frac{E}{K_{P}}\right)^{\beta} K_{P}-C,
$$

where $q \equiv 1-\tau\left(v_{I}+v_{E}+v_{H}\right)=1-\tau(1-\varphi)$, with $q \in(0,1)$, given that $\sum v_{h}<1$. From (3), we also have $q \equiv 1-\tau(1-\varphi)$.

From the definition of $G_{I}$, and using (1),

$$
G_{I}=v_{I} \tau Y=v_{I} \tau A_{P}\left(\frac{G_{I}}{K_{P}}\right)^{\alpha}\left(\frac{E}{K_{P}}\right)^{\beta} K_{P},
$$

that is, with $e=E / K_{P}$,

$$
\frac{G_{I}}{K_{P}}=v_{I} \tau A_{P}\left(\frac{G_{I}}{K_{P}}\right)^{\alpha} e^{\beta},
$$

or equivalently

$$
\frac{G_{I}}{K_{P}}=\left(v_{I} \tau A_{P}\right)^{1 /(1-\alpha)} e^{\beta /(1-\alpha)} .
$$

Substituting (A2) in (A1) yields

$$
\frac{\dot{K}_{P}}{K_{P}}=q A_{P}^{1 /(1-\alpha)}\left(v_{I} \tau\right)^{\alpha /(1-\alpha)} e^{\beta /(1-\alpha)}-c,
$$

where $c=C / K_{P}$.

Similarly, using (A2), equation (15) can be rewritten as

$$
\frac{\dot{C}}{C}=\sigma\left[s A_{P}^{1 /(1-\alpha)}\left(v_{I} \tau\right)^{\alpha /(1-\alpha)} e^{\beta /(1-\alpha)}-\rho\right] .
$$

From the definition of $G_{E}$, and using (1),

$$
G_{E}=v_{E} \tau Y=v_{E} \tau A_{P}\left(\frac{G_{I}}{K_{P}}\right)^{\alpha}\left(\frac{E}{K_{P}}\right)^{\beta} K_{P},
$$

so that, using (A2),

$$
\frac{G_{E}}{K_{P}}=v_{E} \tau A_{P}^{1 /(1-\alpha)}\left(v_{I} \tau\right)^{\alpha /(1-\alpha)} e^{\beta /(1-\alpha)}=v_{E} A_{P}^{1 /(1-\alpha)} v_{I}^{\alpha /(1-\alpha)} \tau^{1 /(1-\alpha)} e^{\beta /(1-\alpha)} .
$$


Equation (8) gives

$$
\frac{\dot{E}}{E}=A_{E}\left[\left(\frac{G_{E}}{K_{P}}\right)\left(\frac{K_{P}}{E}\right)\right]^{\eta}\left[\left(\frac{G_{I}}{K_{P}}\right)\left(\frac{K_{P}}{E}\right)\right]^{\mu}=A_{E}\left(\frac{G_{E}}{K_{P}}\right)^{\eta}\left(\frac{G_{I}}{K_{P}}\right)^{\mu} e^{-(\eta+\mu)},
$$

so that, using (A2) and (A5),

$$
\frac{\dot{E}}{E}=A_{E} \frac{\left[v_{E} A_{P}^{1 /(1-\alpha)} v_{I}^{\alpha /(1-\alpha)} \tau^{1 /(1-\alpha)} e^{\beta /(1-\alpha)}\right]^{\eta}}{\left(v_{I} \tau A_{P}\right)^{-\mu /(1-\alpha)} e^{-\beta \mu /(1-\alpha)}} e^{-(\eta+\mu)} .
$$

This expression can be rewritten as

$$
\frac{\dot{E}}{E}=A v_{E}^{\eta} v_{I}^{(\alpha \eta+\mu) /(1-\alpha)} \tau^{(\eta+\mu) /(1-\alpha)} e^{\omega},
$$

where $A \equiv A_{E} A_{P}^{(\eta+\mu) /(1-\alpha)}$, and

$$
\omega \equiv(\eta+\mu)\left[-1+\frac{\beta}{1-\alpha}\right]=\frac{\eta+\mu}{1-\alpha}(\alpha+\beta-1)<0,
$$

given that $\alpha+\beta<1$.

Combining equations (A3), (A4), and (A6) yields

$$
\begin{gathered}
\frac{\dot{c}}{c}=\Gamma\left(v_{I} \tau\right)^{\alpha /(1-\alpha)} e^{\beta /(1-\alpha)}-\sigma \rho+c, \\
\frac{\dot{e}}{e}=A v_{E}^{\eta} v_{I}^{(\alpha \eta+\mu) /(1-\alpha)} \tau^{(\eta+\mu) /(1-\alpha)} e^{\omega}-\frac{q A_{P}^{1 /(1-\alpha)}\left(v_{I} \tau\right)^{\alpha /(1-\alpha)}}{e^{-\beta /(1-\alpha)}}+c,
\end{gathered}
$$

where

$$
\Gamma \equiv A_{P}^{1 /(1-\alpha)}(\sigma s-q) .
$$

This expression is negative (positive) if $\sigma$ is lower (higher) than the ratio $q / s$ :

$$
\operatorname{sg}(\Gamma)=\operatorname{sg}\left(\sigma-s^{-1} q\right) .
$$

To investigate the dynamics in the vicinity of the steady state, the system (A7)-(A8) can be linearized to give

$$
\left[\begin{array}{c}
\dot{c} \\
\dot{e}
\end{array}\right]=\left[\begin{array}{ll}
a_{11} & a_{12} \\
a_{21} & a_{22}
\end{array}\right]\left[\begin{array}{l}
c-\tilde{c} \\
e-\tilde{e}
\end{array}\right]
$$


where the $a_{i j}$ are given by

$$
\begin{gathered}
a_{11}=\tilde{c}, \quad a_{21}=\tilde{e}, \\
a_{22}=\omega A v_{E}^{\eta} v_{I}^{(\alpha \eta+\mu) /(1-\alpha)} \tau^{(\eta+\mu) /(1-\alpha)} \tilde{e}^{\omega}-\frac{\beta q A_{P}^{1 /(1-\alpha)}\left(v_{I} \tau\right)^{\alpha /(1-\alpha)}}{(1-\alpha) \tilde{e}^{-\beta /(1-\alpha)}}<0, \\
a_{12}=\frac{\beta \tilde{c}}{1-\alpha} \Gamma\left(v_{I} \tau\right)^{\alpha /(1-\alpha)} \tilde{e}^{\omega /(\eta+\mu)},
\end{gathered}
$$

where $\tilde{e}$ and $\tilde{c}$ denote the stationary values of $e$ and $c$, and $\operatorname{sg}\left(a_{12}\right)=\operatorname{sg}(\Gamma){ }^{13}$

From (A7), setting $\dot{c}=0$ yields

$$
\tilde{c}=\sigma \rho-\Gamma\left(v_{I} \tau\right)^{\alpha /(1-\alpha)} \tilde{e}^{\beta /(1-\alpha)} .
$$

Similarly, from (A8), setting $\dot{e}=0$ yields

$$
\tilde{c}=q A_{P}^{1 /(1-\alpha)}\left(v_{I} \tau\right)^{\alpha /(1-\alpha)} \tilde{e}^{-\beta /(1-\alpha)}-A v_{E}^{\eta} v_{I}^{(\alpha \eta+\mu) /(1-\alpha)} \tau^{(\eta+\mu) /(1-\alpha)} \tilde{e}^{\omega} .
$$

From these two equations, it can be seen that the slopes of the $C C$ and $E E$ curves are given by

$$
\begin{gathered}
\left.\frac{d \tilde{c}}{d \tilde{e}}\right|_{C C}=-\frac{a_{12}}{a_{11}}=-\frac{\beta \Gamma}{1-\alpha}\left(v_{I} \tau\right)^{\alpha /(1-\alpha)} \tilde{e}^{\omega /(\eta+\mu)}, \\
\left.\frac{d \tilde{c}}{d \tilde{e}}\right|_{E E}=-\frac{a_{22}}{a_{21}}>0 .
\end{gathered}
$$

Thus, whereas $E E$ always has a positive slope, the slope of $C C$ is upward(downward-) sloping if $\Gamma$ is negative (positive).

$c$ is a jump variable, whereas $e$ is predetermined over time. Saddlepath stability requires one unstable (positive) root. To ensure that this condition holds, the determinant of the Jacobian matrix of partial derivatives of the dynamic system (A11), $\Delta$, must be negative, that is, $\Delta=a_{11} a_{22}-a_{12} a_{21}<0$. If $a_{12}>0$, this condition is always satisfied; $C C$, in that case has a negative slope (see the upper panel of Figure 1). If $a_{12}<0$, it requires $-a_{12} / a_{11}<$ $-a_{22} / a_{21}$, that is, $E E$ must be steeper than $C C$, as shown in the lower panel

\footnotetext{
${ }^{13}$ Note that from $(\mathrm{A} 3),(\mathrm{A} 4)$ and $(\mathrm{A} 6)$, we also have $a_{22}=\omega \gamma-\beta(\gamma+\tilde{c}) /(1-\alpha)$.
} 
of Figure 1. Note that if $\sigma$ is sufficiently low, $\Gamma<0$ and $a_{12}<0$ (see (A10)). The slope of the saddlepath $S S$, which is given by $-a_{12} /(\tilde{c}-\nu)$, where $\nu$ is the negative root of the system, is thus positive (negative) if $\Gamma$ is negative (positive).

Equation (A12) can be substituted in (A8) with $\dot{e}=0$ to yield the implicit form

$F(\tilde{e})=A v_{E}^{\eta} v_{I}^{(\alpha \eta+\mu) /(1-\alpha)} \tau^{(\eta+\mu) /(1-\alpha)} \tilde{e}^{\omega}-\sigma s A_{P}^{1 /(1-\alpha)}\left(v_{I} \tau\right)^{\alpha /(1-\alpha)} \tilde{e}^{\beta /(1-\alpha)}+\sigma \rho=0$,

given that, from (A9), $\Gamma+q A_{P}^{1 /(1-\alpha)}=\sigma s A_{P}^{1 /(1-\alpha)}$.

To show that the BGE is unique, note first that from (A14), and using (18) and (19), or equivalently (A4) and (A6),

$$
F_{\tilde{e}}=\left(\frac{\Omega}{\gamma}\right)^{1 / \omega}\left[\omega \gamma-\frac{\beta}{1-\alpha}(\gamma+\sigma \rho)\right]
$$

where $\Omega \equiv A v_{E}^{\eta} v_{I}^{(\alpha \eta+\mu) /(1-\alpha)} \tau^{(\eta+\mu) /(1-\alpha)}$. This expression is negative along a BGE with a strictly positive $\gamma$, given that $\omega<0$. Thus, $F(\tilde{e})$ cannot cross the horizontal axis from below. Now, we also have $F(0)=\sigma \rho>0$. Given that $F(\tilde{e})$ is a continuous, monotonically decreasing function of $\tilde{e}$, there is a unique positive value of $\tilde{e}$ that satisfies $F(\tilde{e})=0$. From (A12), there is also a unique positive value of $\tilde{c}$. Thus, the BGE is unique.

Equations (A12) and (A14) can be used to examine the impact of changes in spending shares and the tax rate on the steady-state levels of $c$ and $e$. In particular, using the implicit function theorem, it can be established that $\partial \tilde{e} / \partial v_{I}=-F_{v_{I}} / F_{\tilde{e}}$ is in general ambiguous. Given that, from (A15), $F_{\tilde{e}}<0$, $\operatorname{sg}\left(\partial \tilde{e} / \partial v_{I}\right)=\operatorname{sg}\left(F_{v_{I}}\right)$. In turn, $F_{v_{I}}$ can be shown to be equal to, in the "neutral" case where $d v_{I}=-d v_{E}$ (see Proposition 3 ),

$$
F_{v_{I}}=\frac{-\eta \gamma}{v_{E}}+\frac{(\alpha \eta+\mu) \gamma}{(1-\alpha) v_{I}}-\frac{\alpha(\gamma+\sigma \rho)}{(1-\alpha) v_{I}}
$$

Suppose that $v_{H}=\varphi=0$ so that initially $v_{E}=1-v_{I}$. Thus, $F_{v_{I}}<0$ if $\mu=0$, so that $\partial \tilde{e} / \partial v_{I}<0$ also.

In general, from (A12),

$$
\frac{\partial \tilde{c}}{\partial v_{I}}=-\Gamma\left(v_{I} \tau\right)^{\alpha /(1-\alpha)} \tilde{e}^{\beta /(1-\alpha)}\left[\frac{\alpha v_{I}^{-1}}{1-\alpha}+\frac{\beta}{\tilde{e}(1-\alpha)}\left(\frac{\partial \tilde{e}}{\partial v_{I}}\right)\right] .
$$


Similarly, from (A4),

$$
\frac{\partial \gamma}{\partial v_{I}}=s \sigma A_{P}\left(v_{I} \tau\right)^{\alpha /(1-\alpha)} \tilde{e}^{\beta /(1-\alpha)}\left[\frac{\alpha v_{I}^{-1}}{1-\alpha}+\frac{\beta}{\tilde{e}(1-\alpha)}\left(\frac{\partial \tilde{e}}{\partial v_{I}}\right)\right]
$$

Denoting $\varepsilon_{\tilde{e} / v_{I}}=\left(\partial \tilde{e} / \partial v_{I}\right)\left(v_{I} / \tilde{e}\right)$, and given that $\Gamma>0$ in Figure 2, we therefore have

$$
\operatorname{sg}\left(\frac{\partial \gamma}{\partial v_{I}}\right)=-\operatorname{sg}\left(\frac{\partial \tilde{c}}{\partial v_{I}}\right)=\operatorname{sg}\left(\frac{\alpha}{\beta}+\varepsilon_{\tilde{e} / v_{I}}\right)
$$

If $\varepsilon_{\tilde{e} / v_{I}}<0$ (which is always the case if $\mu=0$ or more generally if $\mu / \eta$ is small), the effect on growth is positive if $\alpha / \beta>-\varepsilon_{\tilde{e} / v_{I}}$. If $\varepsilon_{\tilde{e} / v_{I}}>0$ the effect on growth is always positive. Graphically, it can be verified from (A12) and (A14) that a rise in $v_{I}$ always leads to a shift in $C C$ to the left (given that $\Gamma>0$ ), whereas the shift in $E E$ can be either to the right (upper panel of Figure 2) or the left (lower panel).

The impact effect of a rise in $v_{I}$ on the consumption-private capital ratio, given that $d e_{0} / d v=0$, is

$$
\frac{\partial c_{0}}{\partial v_{I}}=\frac{\partial \tilde{c}}{\partial v_{I}}+\frac{a_{12}}{\tilde{c}-\nu}\left(\frac{\partial \tilde{e}}{\partial v_{I}}\right)
$$

which is also ambiguous in general, given that $\partial \tilde{c} / \partial v_{I}$ is ambiguous. If $\partial \tilde{e} / \partial v_{I}$ $<0$, given that $a_{12}>0$, then $\partial c_{0} / \partial v_{I}<0$ if $\partial \tilde{c} / \partial v_{I}<0$, as shown in the upper panel of Figure 2. 


\section{References}

Agénor, Pierre-Richard, "Infrastructure, Public Education and Growth with Congestion Costs," Working Paper No. 43, Centre for Growth and Business Cycle Research, University of Manchester (December 2004).

—_, "Infrastructure Investment, Maintenance Expenditure, and Endogenous Growth," work in progress, University of Manchester (May 2005a).

—, "Optimal Taxation and Growth with Productive Public Goods," work in progress, University of Manchester (August 2005b).

Albala-Bertrand, José M., and Emmanuel C. Mamatzakis, "The Impact of Public Infrastructure on the Productivity of the Chilean Economy," Review of Development Economics, 8 (June 2004), 266-78.

Baier, Scott L., and Gerhard Glomm, "Long-run Growth and Welfare Effects of Public Policies with Distortionary Taxation," Journal of Economic Dynamics and Control, 25 (December 2001), 1007-42.

Barro, Robert J., "Government Spending in a Simple Model of Endogenous Growth," Journal of Political Economy, 98 (October 1990), s103-s25.

Barro, Robert J., and Xavier Sala-i-Martin, "Public Finance in Models of Economic Growth," Review of Economic Studies, 59 (October 1992), 645-61.

Blankenau, William F., and Nicole B. Simpson, "Public Education Expenditures and Growth," Journal of Development Economics, 73 (April 2004), 583-605.

Bose, Niloy, M. Emranul Haque, and Denise R. Osborn, "Public Expenditure and Economic Growth: A Disaggregated Analysis for Developing Countries," unpublished, University of Manchester (June 2003).

Calderón, César, and Luis Servén, "The Effects of Infrastructure Development on Growth and Income Distribution," Policy Research Working Paper No. No. 3400, World Bank (September 2004).

Cassou, Steven P., and Kevin J. Lansing, "Tax Reform with Useful Public Expenditure," unpublished, Federal Reserve Bank of San Francisco (April 2003).

Chang, Wen-Ya, "Government Spending, Endogenous Labor, and Capital Accumulation," Journal of Economic Dynamics and Control, 23 (August 1999), $1225-42$.

Chiu, Ru-Lin, "The Intratemporal Substitution between Government Spending and Private Consumption: Empirical Evidence from Taiwan," Asian Economic Journal, 15 (September 2001), 313-24.

Corsetti, Giancarlo, and Nouriel Roubini, "Optimal Government Spending and Taxation in Endogenous Growth Models," Working Paper No. 5851, National 
Bureau of Economic Research (December 1996).

Dasgupta, Dipankar, "Growth versus Welfare in a Model of Nonrival Infrastructure," Journal of Development Economics, 58 (April 1999), 359-85.

Easterly, William, and Sergio Rebelo, "Fiscal Policy and Economic Growth," Journal of Monetary Economics, 32 (December 1993), 417-58.

Eicher, Theo, and Stephen J. Turnovsky, "Scale, Congestion, and Growth," Economica, 67 (August 2000), 325-46.

Fiaschi, David, "Growth and Inequality in an Endogenous Fiscal Policy Model with Taxes on Labor and Capital," European Journal of Political Economy, 15 (November 1999), 727-46.

Fisher, Walter H., and Stephen Turnovsky, "Public Investment, Congestion, and Private Capital Accumulation," Economic Journal, 108 (March 1998), 399-413.

Futagami, Koichi, Yuichi Morita, and Akihisa Shibata, "Dynamic Analysis of an Endogenous Growth Model with Public Capital," in Endogenous Growth, ed. by Torben M. Andersen and Karl O. Moene, Basil Blackwell (Oxford: 1993).

Glomm, Gerhard, and B. Ravikumar, "Productive Govenment Expenditures and Long-Run Growth," Journal of Economic Dynamics and Control, 21 (January 1997), 183-204.

Gupta Sanjeev, Benedict Clements, Emanuele, Baldacci, and Carlos MulasGranados, "Fiscal Policy, Expenditure Composition, and Growth in LowIncome Countries," Journal of International Money and Finance, 24 (April 2005), 441-64.

Hanushek, Eric, and Dennis D. Kimko, "Schooling, Labor-Force Quality, and the Growth of Nations," American Economic Review, 90 (December 2000), 1184-208.

Karras, Georgios, "Government Spending and Private Consumption: Some International Evidence," Journal of Money, Credit, and Banking, 26 (February 2004), 9-22.

Lee, Jisoon, "Optimal Size and Composition of Government Spending," Journal of the Japanese and International Economies, 6 (June 1992), 423-39.

McGrattan, Ellen R., Richard Rogerson, and Randall Wright, "An Equilibrium Model of the Busines Cycle with Household Production and Fiscal Policy," International Economic Review, 38 (May 1997), 267-90.

Miller, James, and Christopher Tsoukis, "On the Optimality of Public Capital for Long-run Economic Growth," Applied Economics, 33 (July 2001), 111729 . 
Okubo, Masakatsu, "Intertemporal Substitution between Private and Govenrment Consumption: The Case of Japan," Economics Letters, 79 (April 2003), $75-81$.

Piras, Romano, "Growth, Congestion of Public Goods, and Second-Best Optimal Policy," Working Paper No. 2004-5, Fondazione Eni Enrico Mattei (January 2004).

Rioja, Felix K., "Productiveness and Welfare Implications of Public Infrastructure: A Dynamic Two-Sector General Equilibrium Analysis," Journal of Development Economics, 58 (April 1999), 387-404.

Rivas, Luis A., "Income Taxes, Spending Composition and Long-Run Growth," European Economic Review, 47 (June 2003), 477-503.

Tsoukis, Chris, and Nigel J. Miller, "Public Services and Endogenous Growth," Journal of Policy Modeling, 25 (April 2003), 297-307.

Turnovsky, Stephen J., "Optimal Tax, Debt, and Expenditure Policies in a Growing Economy," Journal of Public Economics, 60 (April 1996), 21-44.

- "Fiscal Policy in a Growing Economy with Public Capital," Macroeconomic Dynamics, 1 (- 1997), 615-39.

—_, "Fiscal Policy, Elastic Labor Supply, and Endogenous Growth," Journal of Monetary Economics, 45 (February 2000), 185-210.

—, "The Transitional Dynamics of Fiscal Policy: Long-Run Capital Accumulation and Growth," Journal of Money, Credit, and Banking, 36 (October 2004), 883-910.

Turnovsky, Stephen J., and Walter H. Fisher, "Composition of Government Expenditure and its Consequences for Macroeconomic Performance," Journal of Economic Dynamics and Control, 19 (May 1995), 747-86.

UNESCO, Education for All Global Monitoring Report 2005: The Quality Imperative, UNESCO (Paris: 2005).

Zagler, Martin, and Georg Durnecker, "Fiscal Policy and Economic Growth," Journal of Economic Surveys, 17 (July 2003), 397-418. 
Figure 1

The Balanced Growth Equilibrium
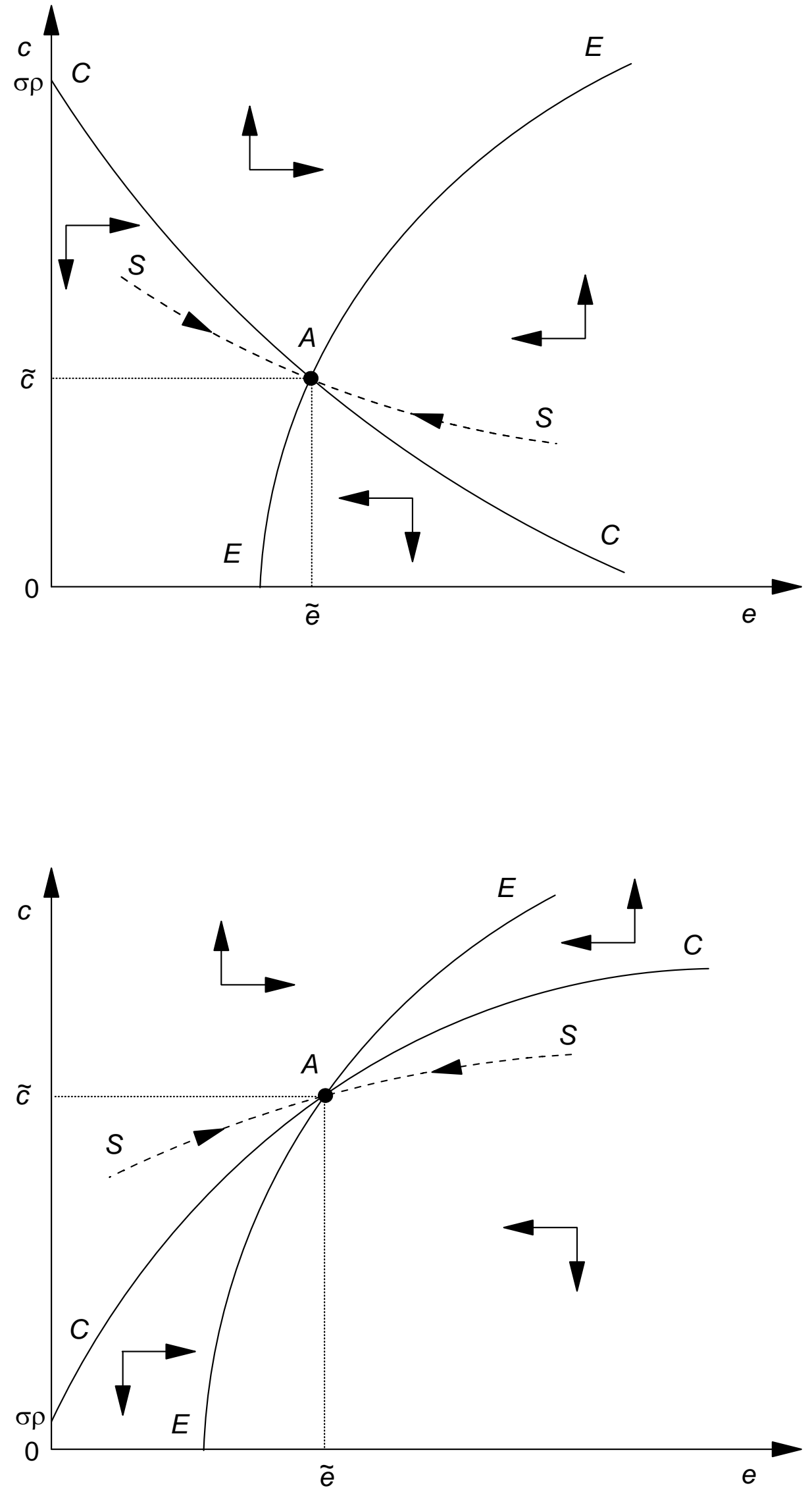
Figure 2

Shift in the Composition of Government Spending from Education to Infrastructure
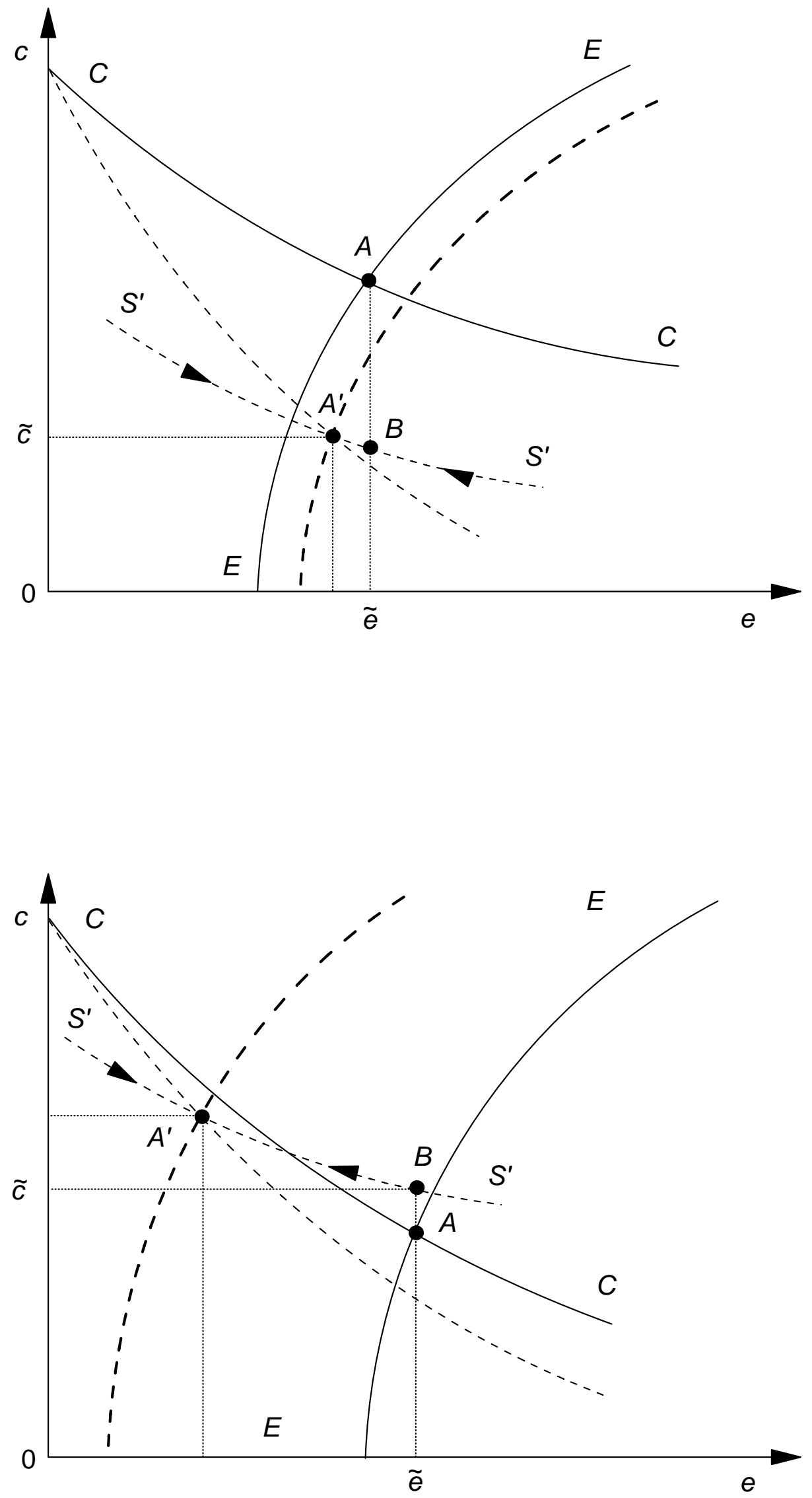